\title{
PRESENTACIÓN
}

\section{Mujeres: los trabajos y los días}

partir de los estudios de género se han procesado nuevas visiones, análisis y reflexiones sobre temas que van desde la cultura hasta el trabajo, pasando en múltiples formas por la política y la legislación. La participación diferenciada de hombres y mujeres en el trabajo no involucra sólo la diferencia salarial; sabido es que, hasta el día de hoy, en muchas empresas donde las mujeres desempeñan el mismo trabajo que los hombres, ellas perciben menor salario. Esto también afecta los papeles de género que se atribuyen a cada quien según el sexo. Hasta hace poco existían trabajos específicos para hombres y otros para mujeres, arguyendo que correspondían a cada quien por "razones biológicas". No obstante, en los últimos 30 años los avances tecnológicos, las luchas políticas y las políticas públicas han empezado a afectar los roles sexuales de hombres y mujeres en el trabajo.

El trabajo de las mujeres, calificado como invisible cuando no se le da un valor en pesos y centavos, es el talón de Aquiles de muchos estudios económicos que al considerar el Producto Interno Bruto (PIB) o a la Población Económicamente Activa (PEA) no miden el aporte del "ama de casa" en la producción y reproducción de la vida cotidiana y la fuerza de trabajo, en el ámbito del hogar o en la producción de animales domésticos. Hasta el siglo XX las mujeres obtuvieron trabajos remunerados y reconocidos. La economía sería otra si a todo trabajo humano se le diera un valor en dinero y éste se contabilizara y sumara a los ingresos y egresos del país. Descubriríamos que todo lo que nos han contado hasta ahora sobre las economías no ha sido totalmente cierto. Pero no es así. La economía, como la conocemos, tiene un sesgo que impide el reconocimiento de ciertos trabajos que no tienen acceso a las estadísticas, mas no por eso dejan de existir.

El número 11 de Desacatos — Mujeres: los trabajos y los días - presenta cuatro artículos sobre el tema mujer y trabajo, que tocan espacios contrastantes entre sí pero que tienen en común la situación laboral de las mujeres y sus relaciones familiares tradicionales y en transición. Este tema presenta muchos retos para los análisis teóricos sobre la función de la participación económica de las mujeres en el campo laboral, la economía doméstica y los roles sexuales tradicionales y nuevos en el hogar.

Los cambios en las relaciones de género han significado, por un lado, una mayor participación de las mujeres en el trabajo asalariado y a la vez mayores decisiones sobre su cuerpo; por el otro, han hecho que las mujeres se conviertan, entre otras cosas, en objeto de políticas públicas nacionales y globales para modificar el crecimiento poblacional. Jules Falquet escribe sobre las relaciones que la Organización de Naciones Unidas ha establecido con las mujeres. En "Mujeres, feminismo y desarrollo: un análisis crítico de las políticas de las instituciones internacionales" analiza los motivos que ha tenido Naciones Unidas en su relación con los movimientos 
de mujeres y feministas; según la autora éstos tienen que ver con la política global denominada neoliberalismo. Así mismo este ensayo ve a "Naciones Unidas como quienes intentan la instalación de una administración mundial global”. Es lacerante la crítica que corta la ancha tela de Naciones Unidas cuando señala: “...la noción ambigua de 'sobrepoblación', muy criticada por las feministas del sur, esconde una teoría racista, sexista y profundamente perversa que presenta a las mujeres latinas, indígenas, negras, árabes y asiáticas como 'demasiado prolíficas' y por tanto culpables de su propia pobreza, responsables del hambre en el mundo y de la presión sobre el medio ambiente". La postura crítica y abstracta de Falquet contrasta con los otros trabajos que se concentran en análisis puntuales.

El mundo de la telecomunicación sin barreras, donde pueden existir videófonos conectados directamente al satélite, que como se ha visto en los últimos sucesos del mes de marzo, pueden transmitir instantáneamente los acontecimientos desde el lugar en donde están sucediendo hasta donde se quiera. La guerra en Irak mostró algunos de estos avances tecnológicos. Estos avances tienen años de estar sucediendo. Josefina Ramírez se asoma al mundo de la revolución tecnológica en "El estrés de las telefonistas: ¿̇amenaza o desafío?" y analiza el mundo de dichas trabajadoras como un tejido social complejo de relaciones laborales, familiares y entre mujeres. Este tejido se trama entre la antigua configuración de un empleo predeterminado y esquematizado y las nuevas tecnologías que cuestionan la capacidad, aptitudes, actitudes y necesidades de las mujeres que atienden la telefonía nacional; y como las telefonistas experimentan cambios en su relación con el trabajo cuando se modifican los sistemas de comunicación, también cambian las formas de percibirse a sí mismas. El estrés se vuelve su modus vivendi. Las telefonistas sometidas cada día más a estrictas reglas de convivencia y de competencia se vuelven parte de una maquinaria que, en un mundo globalizado, va más allá de la empresa.

Algunas mujeres que sin mayores perspectivas deben lograr que los puntos de la tela se junten, quienes carecen de educación y recursos, se dedican a vender sus cuerpos. Jane Howell presenta la vida de mujeres a las que denomina "ambulantes" - "Lupes" se llaman a sí mismas_ y que se dedican a prestar sus servicios sexuales en las calles de Oaxaca. Las clases sociales al interior de este oficio también existen, y las que estudia Jane son las más pobres. Se plantea la paradoja de esta profesión, se encuentra en los límites de los derechos y las mujeres que la ejercen no tienen ninguna garantía social. Cuando envejecen quedan desamparadas en todos los aspectos. La doble moral pervive para todas y para "las buenas conciencias" sobre todo. A través de los testimonios de las "Lupes" se conoce cuáles son sus aspiraciones y para quién trabajan. Casi todas lo hacen para mantener y educar a sus hijos. Ante esta problemática aceptan las situaciones más humillantes, no sólo de los clientes sino de todo el sistema social, vecinos, médicos, policías, etcétera.

En la otra punta de la tela del tejido social se encuentran las mujeres educadas que hablan varios idiomas y gracias a ello pueden tener acceso a ser ejecutivas de alto nivel. Guadalupe Serna muestra en su artículo "Propuestas y hallazgos preliminares para un análisis sobre mujeres ejecutivas en al Ciudad de México" un mundo diferente para las mujeres, en el cual además de sus conocimientos, tiene un alto valor su apariencia. Deben presentarse impecables, a la moda y un poco masculinizadas, para poder estar en posición de mando y tomar importantes decisiones en sus empresas. La presencia física y simbólica de estas mujeres es un paso a la modernidad y un reto a los tradicionales roles sexuales. También esconde la erótica del poder que no se toca en el artículo.

Mujeres ejecutivas que se ven obligadas a olvidar su vida familiar para entrar en el engranaje de la globalización. Porque son mujeres ejecutivas de alto nivel y entre su quehacer cotidiano está el subir y bajar de aviones, viajar por todo el mundo. Su vida privada y familiar está sometida a circunstancias muy particulares. Lo que todas estas mujeres tienen en común es que no importa lo que hagan ni dónde lo hagan; por el sólo hecho de ser mujeres en un mundo en transición, serán trabajadoras de doble jornada o estarán expuestas a los dobles 
vínculos sociales por ser mujeres, esposas y madres, sin hablar de lo subjetivo del sentimiento de culpa que puede significar el no estar mucho tiempo en el hogar.

Mujeres atrapadas en un mundo de dobles vínculos que las obligan a participar en ciertos trabajos para emanciparse y emancipar a sus hijos de la pobreza (como en el caso de las trabajadoras sexuales) y a no olvidar sus roles tradicionales de madres, esposas, hijas obedientes, etc., aunque tengan que compatibilizarlos con ser empleadas tecnificadas con novedosas computadoras o ejecutivas de alto nivel. "Lupes" en las calles de Oaxaca o cifras alcanzadas en la planificación estratégica por instituciones nacionales o internacionales. Estén donde sea, se crean nuevos valores sin que desaparezcan los anteriores.

Las mujeres no están solas en este acontecer; los hombres también se adaptan a estos nuevos valores y papeles. Mercedes Blanco en su comentario "Trabajo y polisemia" hace un excelente análisis de los cuatro artículos y plantea algunas preguntas que hacen reflexionar sobre el futuro de los estudios de género.

Desacatos ha pretendido desde su creación ser un espacio donde se pueda dar la polémica, generar opiniones diversas y críticas. Un espacio desde donde se puede subvertir el orden epistemológico; exponerlo y confrontarlo con nuevas ideas, nuevos conocimientos y análisis. Elsa Guevara presenta en la sección de Esquinas su artículo "Los derechos reproductivos y los hombres. El debate pendiente"; escribe a propósito del artículo de Guillermo Figueroa — publicado en el número de 6 de Desacatos - Argumenta consistentemente sobre la diferencia entre los derechos reprodutivos de hombres y mujeres y fundamenta su posición: "cuando las mujeres exigían 'anticonceptivos para no abortar', 'aborto gratuito para no morir' y reclamaban la maternidad libre y voluntaria, lo hacían considerando el derecho de las mujeres a no sufrir daños en su salud ni arriesgar su vida para que la maternidad fuera una opción y no un destino, pero también estaba presente el rechazo a los embarazos impuestos mediante la violencia física y sexual que vivían las mujeres en su vida cotidiana y las políticas poblacionistas que hacia de la maternidad la única forma de reconocimiento de las mujeres".

En esta misma sección de Esquinas se encuentran otros tres artículos extraordinarios, cada uno desde su perspectiva. "Frida Kahlo. Retrato de la artista como mujer empresaria", de Servando Ortoll y Annette B. Ramírez de Arellano, que nos aporta nuevas luces en el caso de Frida sobre sus dotes empresariales pero también sobre su situación como esposa de un reconocido pintor. El ensayo "Un natural de Santiago Atitlán ante el Oficio de México...”, la causa contra Matheo Pérez, de Rosalba Piazza; y el de Ángela Giglia, “Pierre Bordieu y la perspectiva reflexiva en las ciencias sociales".

El juicio que le hace la Inquisición a Matheo Pérez atraviesa el tiempo para permitirnos vislumbrar las luchas de poder jurisdiccional y las categorías de indio y mestizo y cómo éstas, por las propias políticas coloniales, son arbitrarias que tiñen la identidad de un individuo como parte dos feudos o no. Es a la luz del siglo XXI, y en momentos de reflexión profunda como la que nos ha impuesto la guerra imperial contra Irak, que situaciones como las que vivió Matheo ante el tribunal del Santo Oficio nos acercan la política a la historia y las variadas formas de control que se han establecido para mantener a los imperios que finalmente ante sus propias contradicciones terminan cayendo.

El ensayo de Giglia sobre Bourdieu es un análisis crítico sobre los aportes de éste a la antropología y a la historia y cómo esta propuesta reflexiva permite vislumbrar "un grado superior de libertad" la múltiple libertad individual que lleva a la conciencia y la conciencia que permite vislumbrar al individuo como parte de una sociedad, y sus actos son el referente obligado de la dinámica social, de una ética basada en el bien común, si se quiere pensar en términos humanistas versus economicistas. Esa conciencia es la que nos precipita a la "democracia". No la impuesta con "bombas inteligentes", sino la otra, la que tal vez sueña Jan de Vos en el libro Una tierra para sembrar sueños. Historia reciente de la Selva Lacandona, 1950-20oo, que reseña Xóchitl Leyva.

En remembranza de que este año se cumplen 50 de que en México se dio la participación de las mujeres en 
la política a través del derecho a votar, el derecho a elegir y a ser elegidas, se pensó hacer un homenaje a las mujeres trabajadoras que desde los tiempos de la Revolución demandaban ese derecho. En la sección Testimonios se presentan dos crónicas periodísticas del Primer Congreso de Mujeres Obreras y Campesinas realizado en la Ciudad de México en octubre de 1931. Ahí las voces de algunas líderes aparecen claras y contundentes sobre la demanda de sus derechos políticos.

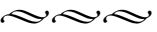

La oportunidad de trabajar para un espacio de reflexión y análisis de propuestas novedosas y distintas formas de pensar, ha sido uno de los retos más estimulantes que me encargara Rafael Loyola, director del CIESAS, y el Consejo Editorial de la revista Desacatos. He tratado de responder cabalmente al reto y desde que me hice cargo de la revista han aparecido ocho números. Esto no hubiera sido posible sin el apoyo y la ayuda de muchas personas a quienes quiero agradecer: a los compañeros y compañeras de la Unidad CIESAS Istmo; a Mara Alfaro, Jaime Pérez, Berna Leyva, Andrés Castellanos, Ramiro Pablo, Estela Guzmán, Fabiola Bautista, Agustín Martínez y especialmente a quien ha sido una compañera de viaje editorial, Verónica Loera y Chávez. Mas como todo principio tiene un fin, el periodo por el que me comprometí a la edición de la revista ha terminado y sólo me queda agradecer la oportunidad que me dieron de servir al Centro de Investigaciones y Estudios Superiores en Antropología Social de esta manera.

La revista Desacatos cumple con este número una etapa de trabajo. Nuevas tareas le esperan y será Daniela Spenser la encargada de llevarlas a cabo, a ella se le entrega la estafeta. 